\title{
Newborn TSH concentration and its association with cognitive development in healthy boys
}

\author{
Carmen Freire, Rosa Ramos, Esperanza Amaya, Mariana F Fernández, Piedad Santiago-Fernández ${ }^{1}$, \\ Maria-Jose Lopez-Espinosa ${ }^{2,3}$, Juan-Pedro Arrebola and Nicolas Olea \\ Laboratory of Medical Investigations, San Cecilio University Hospital, University of Granada, CIBER de Epidemiología y Salud Pública (CIBERESP), \\ Avenida Madrid s/n, 18071 Granada, Spain, ${ }^{1}$ Endocrinology Unit, Ciudad de Jaén Hospital, 23007 Jaén, Spain, ${ }^{2}$ Department of Social and Environmental \\ Health Research, London School of Hygiene and Tropical Medicine, WC1H 9SH London, UK and ${ }^{3}$ Centre for Public Health Research (CSISP), Conselleria de \\ Sanitat, Generalitat Valenciana, CIBER de Epidemiología y Salud Pública (CIBERESP), 46020 Valencia, Spain
}

(Correspondence should be addressed to C Freire; Email: cfreire@ugr.es)

\begin{abstract}
Objective: An association between thyroid function during pregnancy or infancy and neurodevelopment in children has been demonstrated. We aimed to investigate whether newborn TSH concentrations are related to subsequent neurocognitive development.

Design: We conducted a longitudinal study on 178 children from a general population birth cohort in Granada (Spain) born in 2000-2002.

Methods: TSH concentrations were measured in umbilical cord blood, and cognitive functions were assessed at 4 years of age using the McCarthy's scales of children's abilities (MSCA). Organochlorine (OC) compound concentrations and the combined oestrogenicity (total effective xeno-oestrogenic burden (TEXB)) were also determined in the placentae.

Results: Mean newborn TSH was $3.55 \mathrm{mU} / \mathrm{l}$ (range $=0.24-17 \mathrm{mU} / \mathrm{l}$ ). In multivariate regression analyses, adjusting for maternal and child characteristics, higher newborn TSH concentrations showed a decrease of 3.51 and 3.15 points on the MSCA general cognitive and executive function scores respectively and were associated with a higher risk of scoring below the 20th percentile (P20) on the quantitative score (odds ratio $(\mathrm{OR})=2.64$ ). Children with TSH in the upper quartile (4.19-17.0 mU/l) were at higher risk of scoring $<$ P20 on span memory $(\mathrm{OR}=5.73)$, whereas children with TSH in the second quartile (2.05-2.95 mU/l) were at lower risk of scoring $<\mathrm{P} 20$ on the verbal scale $(\mathrm{OR}=0.24)$. Neonatal TSH status was also associated with general cognitive and executive function outcomes when controlling for prenatal exposure to OCs or placental TEXB.

Conclusions: Newborn thyroid hormone status expressed by TSH in cord blood may adversely affect later cognitive function. A more thorough screening for neonatal thyroid deficiency is warranted.
\end{abstract}

European Journal of Endocrinology 163 901-909

\section{Introduction}

Thyroid hormones (THs) are essential for the fetal and postnatal human development and for the regulation of neuropsychological function in children and adults (1). THs regulate the processes of neurogenesis, myelination, dendrite proliferation and synapse formation $(2,3)$. Although THs are required throughout gestation, the fetal thyroid gland does not produce its own TH in appreciable amounts until the third trimester $(4,5)$. Accordingly, an increasing number of epidemiological studies and case reports have strongly supported the notion that impaired maternal thyroid function during early gestation may result in poor fetal neurodevelopment (6-10).

Iodine deficiency (ID), which compromises adequate production and secretion of thyroxine $\left(\mathrm{T}_{4}\right)$ by the thyroid, remains the most frequent cause of maternal and fetal TH deficit and therefore of preventable mental retardation (5). Over the past two decades, attention has been drawn to the sub-optimal cognitive or behavioural functioning (which may be sub-clinical) observed in children born to mothers with even mild or moderate ID (10-16) or the developmental implications for children with slight neonatal elevations of TSH $(17,18)$. Thyroid deficiency during the last two trimesters of pregnancy and the first few months post delivery can also result in mental and physical retardation and sometimes neurological deficits, a condition known as cretinism (19). Neurological features are less severe in neonatal hypothyroidism than in prenatal hypothyroidism, although deficits in memory and intelligence quotient may persist (2). Overall, few studies have addressed whether subsequent development can be influenced by moderate thyroid dysfunction in neonates or even by variations within the normal range of TH levels. 
Recent studies indicate that exposure to certain environmental contaminants may also interfere with maternal thyroid status during pregnancy and with thyroid function in newborns (20-26). Hence, it has been speculated that some of the neurotoxic effects of early exposure to the environmental chemicals may result from thyroid disruption $(27,28)$. Nonetheless, the influence of early exposure to endocrine disruptors (ED) on thyroid function and therefore children's neurodevelopment remains to be elucidated.

In a previous study of a mother-child cohort, we analysed the influence on neonatal $\mathrm{TH}$ status of placental exposure to certain organochlorine (OC) pesticides with known ED activity (C Freire, M J LopezEspinosa, M F Fernández, J M Molina-Molina, R Prada and N Olea, unpublished observations). In this study, we examined the association of newborn TSH concentrations with cognition at 4 years of age in the same cohort (in Granada, Southern Spain). We hypothesised that infants with poorer thyroid status, manifested by higher TSH levels, would have lower scores in subsequent cognitive testing. This investigation is part of the 'Infancia y Medio Ambiente (Environment and Childhood) (INMA) Project', a prospective multicentre study in Spain (29).

\section{Materials and methods}

\section{Subject recruitment}

From 2000 to 2002, 700 eligible mother-son pairs registered at the San Cecilio University Hospital were enrolled at delivery, establishing the INMA-Granada cohort, with the initial aim of investigating chronic exposure to ED and urogenital malformations in newborn boys. Exclusion criteria were the maternal presence of serious chronic disease, such as diabetes, hypertension or thyroid disease; a pregnancy complication that could affect growth or development and a non-residence in the hospital referral area (30). In 2005-2006, 220 of the 700 boys aged 4 years and their mothers were randomly invited to participate in the physical examination and cognitive testing $(31,32)$.

Approval by committee for human subjects A written informed consent was obtained from parents before the study, which was approved by the Ethics Committee of the San Cecilio University Hospital, in accordance with the Code of Ethics of the World Medical Association (Declaration of Helsinki) for experiments involving humans.

The study was approved by the Institutional Ethical Committee of the Hospital, and signed informed consent was also obtained from the women who agreed to participate.

\section{TSH determination}

TSH was measured in a cord blood sample spotted on a filter paper (Schleicher \& Schuell no. 2992), which is routinely obtained at delivery for the screening programme of neonatal congenital hypothyroidism (33). TSH concentrations were determined by using time-resolved sandwich fluoroimmunoassay (AutoDELFIA, Perkin Elmer/Wallac, Turku, Finland) at the Centre for the Early Detection of Metabolopathies in Neonates in San Juan de Dios Hospital (Granada, Spain). The limit of detection (LD) was $0.01 \mathrm{mU} / \mathrm{l}$. A cord blood level $\geq 14 \mathrm{mU} / \mathrm{l}$ is established in the Centre's laboratory to trigger the protocol for the study and for the confirmation of neonatal hypothyroidism.

\section{Quantification of OC pesticides and oestrogenicity in the placenta}

Placentas were collected at delivery from the cohort, and 17 OC pesticides (dichlorodiphenyltrichloroethane (DDT) isomers and metabolites, endosulphan isomers and metabolites, aldrin, endrin, dieldrin, lindane, hexachlorobenzene, methoxychlor and mirex) were extracted from tissue samples by a previously described method, which was developed to separate natural oestrogens ( $\alpha$ fraction) from more lipophilic xeno-oestrogens ( $\beta$ fraction) without destroying either $(34,35)$.

OC pesticide concentration was determined in 308 randomly selected placenta samples by gas chromatography (GC) with electron-capture detection. The compounds were confirmed by GC and mass spectrometry (30). The LD for the studied chemicals ranged from 0.1 to $3.0 \mathrm{ng} / \mathrm{ml}$. For levels below the $\mathrm{LD}$, we considered a value of half the LD.

The total effective xeno-oestrogenic burden (TEXB) of the $\alpha$ fraction $(\alpha$-TEXB) and the $\beta$ fraction $(\beta$-TEXB) was estimated in the placenta samples by using the E-Screen bioassay $(34,35)$. The $\alpha$-TEXB can be considered a marker of the TEXB of environmental organohalogenated oestrogens (35). The LD of TEXB was defined as the concentration needed to produce a significantly different proliferative effect from that observed in the control cells.

\section{Cognitive testing}

The neurocognitive evaluation of the children was performed by two specifically trained psychologists in the Paediatrics Department of our Hospital. Cognitive and motor abilities were assessed using a Spanish adaptation of the McCarthy scales of children's abilities (MSCA) (36), which gives standardised test scores for five domains (quantitative, verbal, memory, perceptual performance and motor). A general cognitive score, which estimates global intellectual function, was calculated by combining the verbal, perceptual 
performance and quantitative scores. A strict protocol was applied to avoid inter-observer variability (37), which was $<5 \%$. Psychologists involved in the cognitive testing of the children were unaware of the design sequence of the study.

At the same time as the children were evaluated, the parents completed a self-reported questionnaire on parent-to-infant attachment and another questionnaire on mental health, considered as effect modifiers on infant mental development (38). The parent-to-infant attachment questionnaire consisted of 19 items that assessed the emotional bond of affection experienced by the parent towards the infant (39). The 12-item version of the general mental health questionnaire was used to identify psychological distress and short-term changes in parental mental health.

To further improve our understanding of the specific functions associated with neonatal TSH, the MSCA items were reorganised into the following new outcomes for tasks highly associated with specific neurocognitive functions: verbal memory (items 3 and 7II), working memory (items 5 and 14II), memory span or short-term memory (items 6, 7I and 14I), gross motor (items 9, 10 and 11), fine motor (items 12 and 13) and executive function (items 2, 5, 6, 14II, 15, 17 and 18) (32, 37).

\section{Covariates}

The attending paediatrician and trained interviewers gathered information at delivery and at the 4-year visit respectively on maternal age, alcohol consumption and cigarette smoking during pregnancy, reproductive history, parity, pre-pregnancy body mass index (BMI), duration of breastfeeding, maternal and paternal education, marital status and area of residence (urban: city of Granada; metropolitan: towns of $>20000$ inhabitants in city residential belt; sub-urban: towns of 10 000-20 000 inhabitants; rural: <10 000 inhabitants). Information on gestational age and anthropometric measurements at birth were obtained from medical records. Covariates considered for inclusion in the statistical analysis were expressed as shown in Table 1.

Complete cognitive outcome data and information on cord blood TSH concentration and covariates were available for 178 subjects from the cohort $(n=220)$. Information on the former and prenatal exposure to OCs and TEXB in the placenta was available for a subset of 101 of the 178 children $(57 \%)$ in this study. No differences in any study characteristics were found between this subset and the children without TSH measurements $(n=42)$ (data not shown).

\section{Statistical analysis}

MSCA general cognitive, perceptual performance and executive function scores were normally distributed and were standardised to a mean of 100 points with an S.D. of 15 to homogenise the scales. A cut-off point corresponding to the 20th percentile (P20) was used to categorise the outcomes with a non-normal distribution. We used simple linear regression or ANOVA to examine the relationship of covariates with general cognitive scores.

TSH values were transformed into natural logarithms (log transformed) to improve the normality. We used adjusted general additive models (GAM) to evaluate the linearity of the relationship between general cognitive scores and TSH levels, comparing models with TSH in a linear and a non-linear manner (a cubic smoothing spline with 2-4 degrees of freedom) by means of likelihood ratio tests (Fig. 1). Because no significant improvement in the model was obtained with non-linear models, we first treated TSH as a continuous variable. In a second analysis, TSH was categorised into quartiles.

The strength of the unadjusted and adjusted associations between the outcome scores and TSH levels was measured by calculating coefficients $(\beta)$ and odds ratios (ORs) for linear and logistic regression models. Variables associated with the general cognitive score at a significance level of $P<0.20$ in the bivariate analysis or whose inclusion in the models changed TSH effect estimates by $>10 \%$ were considered confounders. All multivariate models controlled for maternal age $(\geq 32$ years) and gestational age (continuous), regardless of their statistical significance. The potential confounding of exposure to OC and TEXB levels in the placenta was examined in a further regression analysis of the association of TSH with general cognitive and executive function outcomes. Concentrations of OCs and TEXB values were categorised using the LD cut-off points, except for $p, p^{\prime}$-dichlorodiphenyldichloroethylene ( $p, p^{\prime}$-DDE) (detected in $\geq 90 \%$ of the placenta extracts), which was introduced as continuous (ng/g of placenta). In all the cases, the level of significance was $P \leq 0.05$. STATA version 9.2 (STATA Corporation, College Station, TX, USA) was used for the analyses.

\section{Results}

Mean (s.D., range) newborn TSH was 3.55 (2.54, 0.24-17) $\mathrm{mU} / \mathrm{l}$, and only three newborns had a TSH level above $14 \mathrm{mU} / \mathrm{l}$ (laboratory reference value). Repeated measurement analyses confirmed the TSH levels of these three babies, none of whom were diagnosed with thyroid disorder. Mean (s.D.) infant birth weight was 3289 (487) g, and gestational length was 39 (1.8) weeks; maternal age at delivery was 31 (5) years, and pre-pregnancy BMI was $23.5(4.0) \mathrm{kg} / \mathrm{m}^{2}$. Around $22 \%$ of women smoked during pregnancy, $47 \%$ were primiparous, $85 \%$ breastfed the child, $15 \%$ of mothers and $16 \%$ of fathers had university education and $64 \%$ of the families lived in urban or metropolitan settings. TSH concentrations were slightly higher in infants with lower birth weight (by $-0.66 \mathrm{mU} / \mathrm{l}$ per $\mathrm{kg}$; 95\% confidence interval $(\mathrm{CI})=-1.4,0.11$; 
Table 1 MSCA general cognitive scores by characteristics of the study population from the INMA-Granada cohort, 2000-2006 ( $n=178)$.

\begin{tabular}{|c|c|c|c|}
\hline & & \multicolumn{2}{|c|}{ General cognitive score ${ }^{a}$} \\
\hline & & Mean (s.D.) & $P$ value* \\
\hline \multicolumn{4}{|l|}{ Child variables } \\
\hline Gestational age (weeks) (median) & 39 & - & 0.05 \\
\hline Birth weight (g) (mean) & 3289 & - & 0.17 \\
\hline Birth length (cm) (median) & 51 & - & 0.04 \\
\hline Cord blood TSH (mU/l) (median) & 2.95 & - & 0.52 \\
\hline Age at evaluation (months) (mean) & 51 & - & 0.008 \\
\hline School term at evaluation (\%) & & & 0.002 \\
\hline 3rd year, 3rd term & 38.2 & $96.6(15.2)$ & \\
\hline 4th year, 1 st term & 29.8 & $99.1(13.0)$ & \\
\hline 4th year, 2 nd or 3rd term & 32.0 & $105.4(13.5)$ & $\_\S$ \\
\hline Area of residence at evaluation (\%) & & & 0.05 \\
\hline Rural & 15.2 & $97.8(15.2)$ & \\
\hline Sub-urban & 20.8 & $96.8(16.4)$ & \\
\hline Metropolitan & 48.3 & $100.3(13.3)$ & \\
\hline Urban & 15.7 & $106.4(13.0)$ & $-{ }^{\dagger}$ \\
\hline \multicolumn{4}{|l|}{ Maternal variables } \\
\hline Age at delivery (years) (median) & 31 & - & 0.84 \\
\hline Parity (\%) & & & $<0.001$ \\
\hline 0 & 46.6 & $105.3(12.0)$ & \\
\hline 1 & 38.8 & $95.5(15.0)$ & $\_\S$ \\
\hline$\geq 2$ & 14.6 & $95.9(15.1)$ & $\_\neq$ \\
\hline Educational level (\%) & & & 0.03 \\
\hline Up to primary school & 15.2 & $95.8(15.6)$ & \\
\hline Secondary school & 70.2 & $99.8(13.7)$ & $-^{\dagger}$ \\
\hline University & 14.6 & $106.3(15.4)$ & $-^{\ddagger}$ \\
\hline Smoking during pregnancy (\%) & & & 0.74 \\
\hline No & 77.5 & $100.3(14.6)$ & \\
\hline Yes & 22.5 & $99.5(14.1)$ & \\
\hline Breastfeeding (\%) & & & 0.31 \\
\hline No & 14.6 & $96.9(16.3)$ & \\
\hline Yes & 85.4 & $100.1(14.1)$ & \\
\hline Mother-to-infant attachment score (mean) & 74.6 & - & 0.02 \\
\hline Maternal mental health score $(\text { median })^{\mathrm{c}}$ & 10.0 & - & 0.67 \\
\hline \multicolumn{4}{|l|}{ Paternal variables } \\
\hline Educational level (\%) & & & $<0.001$ \\
\hline Up to primary school & 20.8 & $96.5(15.8)$ & \\
\hline Secondary school & 63.5 & $100.1(13.3)$ & \\
\hline University & 15.7 & $105.4(16.3)$ & $-^{\dagger}$ \\
\hline Father-to-infant attachment score (mean) ${ }^{\mathrm{b}}$ & 74.6 & - & 0.13 \\
\hline Paternal mental health score (median) ${ }^{c}$ & 9.1 & - & 0.44 \\
\hline
\end{tabular}

$P=0.09$ ), and infants of fathers with university education were substantially more likely to have lower TSH (by $-1.27 \mathrm{mU} / \mathrm{l} ; 95 \% \mathrm{CI}=-2.20,-0.34 ; P=0.007$ ) (data not shown). Newborn TSH levels did not differ by maternal age, gestational age, parity or other covariates. Mean (s.D., range) age of the boys at psychological testing was $51(2,47-58)$ months, and their general cognitive score was $100.1(14.5,56.9-131)$ points. This score was significantly higher among older children, urban children, those from primiparous mothers and those from parents with university education, and it was positively associated with gestational age, birth length and mother-to-infant attachment score at 4 years of age (Table 1). Perceptual performance scores ranged between 53.1 and 135; the range of the executive function was 58.3-133; verbal, 57.2-133 (22.5\%, <P20); quantitative, 61.5-155 (23.6\%, <P20); memory, 60.4-146 (19.7\%, <P20); motor, 45.7-131 (20.2\%, <P20); span memory, 59.2-133 (15.7\%, <P20); working memory, 76.8-159 (42.7\%, <P20); verbal memory, 54.4-161 (29.2\%, $<$ P20); gross motor, $69.2-137(15.2 \%,<\mathrm{P} 20)$ and fine motor, 52.8-134 (15.7\%, <P20) (data not shown).

Table 2 shows the unadjusted associations between the cord blood TSH levels and children's cognitive test scores. In accordance with our hypothesis, a higher TSH was related to lower MSCA scores. The risk of scoring 


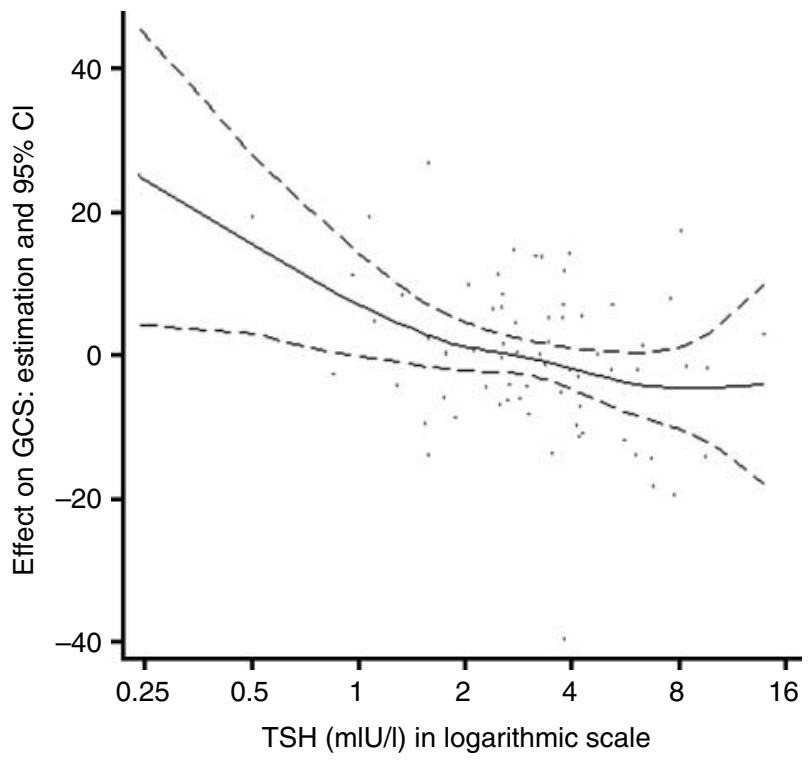

Figure 1 Cubic smoothing association between log-transformed TSH levels and general cognitive scores (GCS) in multivariate analysis.

$<$ P20 on the quantitative scale was greater in children with higher $\mathrm{TSH}$ levels $(\mathrm{OR}=2.25 ; 95 \% \mathrm{CI}=1.20,4.25$; $P=0.01$ ), but no significant association was found with any MSCA outcome score in crude analyses. By contrast, multivariate models adjusted for maternal and child characteristics showed an association between elevated newborn TSH levels as a continuous measure and poorer child functioning in general cognitive, executive function and quantitative areas (Table 3). Thus, higher TSH predicted lower child general cognitive score (by - 3.52; 95\% CI $=-6.81,-0.23 ; P=0.04)$ and executive function score (by $-3.15 ; 95 \% \mathrm{CI}=-6.66,-0.19$; $P=0.05)$, and infants with higher cord blood TSH were more likely to score $<\mathrm{P} 20$ on the quantitative scale $(\mathrm{OR}=2.64 ; 95 \% \quad \mathrm{CI}=1.16,5.54 ; P=0.02)$. These associations with the general cognitive and the quantitative outcomes were also observed when TSH status quartiles were considered. Lower test scores (general cognitive, $-5.42 ; 95 \% \mathrm{CI}=-11.30,-0.61 ; P=0.05$; quantitative, $\quad \mathrm{OR}=4.92 ; 95 \% \quad \mathrm{CI}=1.30, \quad 16.47$; $P=0.02$ ) were found for children with newborn TSH concentrations in the upper quartile $(>4.19 \mathrm{mU} / \mathrm{l})$ versus the first quartile $(<2.05 \mathrm{mU} / \mathrm{l})$, and the risk of delayed span memory function $(<\mathrm{P} 20)$ was higher for children with newborn TSH in the upper quartile $(\mathrm{OR}=5.73 ; 95 \% \mathrm{CI}=0.72,24.67 ; P=0.03)$. Interestingly, newborn TSH in the second quartile had a positive effect on verbal scores (risk for scores $<$ P20 $=0.24$ ) in comparison with children with TSH in the lower quartile. Figure 1 depicts the GAM for the relationship between TSH concentrations and general cognitive scores, showing a positive linear trend.

With the exception of $p, p^{\prime}$-DDE, detected in $92.1 \%$ of the placenta samples and with a mean (s.D.) concentration of $3.09(6.50) \mathrm{ng} / \mathrm{g}$ placenta, the percentage detection of OC pesticides was $<90 \%(n=101)$, ranging from $24.8 \%$ (dieldrin) to $84.2 \%$ (lindane) (data not shown). The TEXB of the $\alpha$ and $\beta$ fractions were above the $\mathrm{LD}$ in 67.3 and $83.2 \%$ of the placenta extracts respectively. Table 4 shows that the negative associations of cord blood TSH status with the general cognitive score (by $-6.34 ; 95 \% \mathrm{CI}=-12.32,-0.36$; $P=0.04)$ and executive function score (by $-7.85 ; 95 \%$ $\mathrm{CI}=-14.04, \quad-1.67 ; P=0.009)$ were also present after simultaneous adjustment for prenatal exposure to the 17 OCs measured. After controlling for TEXB, the association remained significant for the general cognitive score (by $-5.35,95 \% \mathrm{CI}=-10.24,-0.45$; $P=0.03)$ and was marginally significant for executive function score (by $-5.05 ; 95 \% \mathrm{CI}=-10.27,0.18$; $P=0.06)$. However, contrary to expectations, the magnitude of the effect of TSH on cognitive functions was strengthened after adjustment for prenatal OC exposure (change in regression coefficient $>10 \%$ ).

Table 2 Crude coefficients and odds ratios (95\% confidence intervals) for the association between cord blood TSH levels and MSCA outcomes, INMA-Granada cohort, 2000-2006 $(n=178)^{\mathrm{a}}$.

\begin{tabular}{lcr}
\hline MSCA outcomes at 4 years of age & TSH $(\mathrm{mU} / \mathrm{l})^{\mathbf{b}}$ & $\boldsymbol{P}$ value \\
\hline General cognitive $(\beta)$ & $-1.71(-4.90,1.49)$ & 0.29 \\
Verbal (OR) & $1.11(0.62,1.99)$ & 0.72 \\
Perceptual performance $(\beta)$ & $-0.04(-3.30,3.22)$ & 0.98 \\
Quantitative (OR) & $2.26(1.20,4.25)$ & 0.01 \\
Memory (OR) & $1.17(0.63,2.16)$ & 0.61 \\
Span (OR) & $1.19(0.61,2.31)$ & 0.62 \\
Verbal memory (OR) & $1.40(0.82,2.39)$ & 0.22 \\
Working memory (OR) & $1.55(0.95,2.55)$ & 0.08 \\
Motor skills (OR) & $0.71(0.39,1.29)$ & 0.26 \\
Fine motor skills (OR) & $1.12(0.57,2.18)$ & 0.75 \\
Gross motor skills (OR) & $1.19(0.58,2.44)$ & 0.63 \\
Executive function ( $(\beta)$ & $-1.62(-4.79,1.56)$ & 0.32 \\
\hline
\end{tabular}

$\mathrm{OR}$, logistic regression odds ratio; $\beta$, linear regression coefficient. For ORs, the cut-off points correspond to the 20th percentile (reference group > P20). Normal distributed data are standardised (mean: 100; S.D.: 15).

a'Each row represents a model adjusted for child's age and school term and psychologist administering the test. bLog-transformed TSH levels. 
Table 3 Adjusted regression coefficients and odds ratios (95\% confidence intervals) for the effect of cord blood TSH levels (mU/l) on MSCA outcomes, INMA-Granada cohort, 2000-2006 $(n=178)^{\mathrm{a}}$.

TSH quartiles

\begin{tabular}{|c|c|c|c|c|}
\hline \multirow[b]{2}{*}{$\begin{array}{l}\text { MSCA outcomes at } \\
4 \text { years of age }\end{array}$} & \multirow[b]{2}{*}{ Continuous $\mathrm{TSH}^{\mathrm{b}}$} & \\
\hline & & $2.05-2.95$ & $2.96-4.18$ & $4.19-17.0$ \\
\hline General cognitive $(\beta)$ & $-3.52(-6.81,-0.23$ & $-0.36(-6.29,5.67)$ & $-3.03(-8.78,2.74)$ & $-5.42(-11.30,-0.6$ \\
\hline (lorbal (OR) & $118(066=3301$ & $024(005-105)^{*}$ & $0.55(0$ & $1.48(0.38,5.39)$ \\
\hline Perceptual performance $(\beta)$ & $-1.41(-4.87,1.91)$ & $-1.12(-7.28,4.99)$ & $-4.04(-9.99,1.84)$ & $-2.17(-8.31,3.92)$ \\
\hline Quantitative (OR) & $2.64(1.16,5.54)^{\dagger}$ & $1.21(0.31,4.25)$ & $1.28(0.32,4.73)$ & $4.92(1.30,16.47)^{\dagger}$ \\
\hline ry $(\mathrm{OR})$ & $1.61(0.60,3.80)$ & $0.83(0.13,3.60)$ & $0.92(0.18,3.74)$ & $3.51(0.65,15.26)$ \\
\hline Spa & $1.51(0.52,3.94)$ & $0.53(0.07,3.23)$ & $0.32(0.05,2.50)$ & $5.73(0.72,24.67)^{\star}$ \\
\hline Verbal memory (OR) & $1.72(0.86,3.41)$ & $0.69(0.21,2.29)$ & $1.22(0.39,3.71)$ & $1.98(0.62,6.30)$ \\
\hline Working memory (OR) & $1.35(0.76,2.49)$ & $1.03(0.35,2.93)$ & $1.34(0.50,3.77)$ & $1.47(0.54,4.27)$ \\
\hline Motor skills (OR) & $0.65(0.32,1.47)$ & $0.39(0.11,1.87)$ & $0.42(0.13,1.73)$ & $0.80(0.24,3.10)$ \\
\hline Fine motor skills (OR) & $1.48(0.63,3.66)$ & $1.68(0.35,9.12)$ & $2.14(0.54,9.28)$ & $2.31(0.53,11.39)$ \\
\hline Gross motor skills (OR) & $0.69(0.26,1.99)$ & $4.27(0.69,28.84)$ & $0.24(0.02,2.55)$ & $2.49(0.44,16.67)$ \\
\hline Executive function $(\beta)$ & $-3.15(-6.66,-0.19)^{*}$ & $-0.30(-6.51,5.96)$ & $-3.37(-9.46,2.56)$ & $-4.29(-10.56,1.86)$ \\
\hline
\end{tabular}

$\mathrm{OR}$, logistic regression odds ratio; $\beta$, linear regression coefficient. For ORs, the cut-off points correspond to the 20th percentile (reference group $>\mathrm{P} 20$ ). ${ }^{\star} P<0.05 ;{ }^{\dagger} P<0.01$. Normal distributed data are standardised (mean: 100; s.D.: 15).

${ }^{a}$ Each row represents two models: one using continuous TSH and the other using TSH quartiles. All models are adjusted for birth length, gestational age, maternal age, parity, breastfeeding, maternal and paternal education, mother-to infant attachment, child's age and school term and psychologist administering the test.

${ }^{\mathrm{b}}$ Log-transformed TSH levels.

\section{Discussion}

This study of 178 children in Southern Spain born with normal thyroid function yielded evidence of an association between neonatal TSH and the cognitive development of children at 4 years of age, supporting our study hypothesis. Thus, MSCA general cognitive, quantitative and executive function scores appeared to be impaired by higher TSH cord blood levels. Limited data are available on the effect of newborn thyroid status on neurodevelopment, and most reports of associations have described the influence of thyroid status during pregnancy, specifically in relation to reduced $\mathrm{T}_{4}$ levels (5). In addition, infants of fathers with university education had lower TSH, suggesting that neonatal thyroid status may be affected by social conditions. Paternal education and cord blood TSH levels contributed to predict cognitive performance at 4 years of age, consistent with the findings in research on ID that maternal education has a protective role in infant development (40).
The relationship between TH or TSH and cognitive function has mainly been studied in children with congenital hypothyroidism, children of mothers with low TH concentrations during pregnancy or children living in ID areas (41). A number of case-control studies have reported associations between decreased maternal or neonatal $\mathrm{T}_{4}$ and/or triiodothyronine $\left(\mathrm{T}_{3}\right)$ levels and poorer neurodevelopment in children born to mothers with hypothyroxinaemia during pregnancy or in ex-preterm infants, among others $(11,12,42,43)$. Detected neurocognitive deficits include attention deficits $(11,43)$, reduced mental and motor development scores $(12,42,43)$, impaired intelligence and language skills and difficulties in school performance at later ages (11). Interestingly, a cross-sectional analysis of 334 healthy children from two general population cohorts at 4 years of age (from Menorca and Ribera d'Ebre; INMA study) found an association between higher serum TSH levels (2.43-5.01 mU/l) and delayed general cognitive, quantitative, memory, verbal and

Table 4 Regression coefficients (95\% confidence interval) for the effect of cord blood TSH levels (mU/I) on the MSCA general cognitive score and executive function score, adjusted for the placental organochlorine (OC) pesticide and combined oestrogenicity (TEXB) in a sub-sample of 101 children from the INMA-Granada cohort, 2000-2006 ${ }^{\mathrm{a}}$.

\begin{tabular}{lccc}
\hline $\begin{array}{l}\text { MSCA outcomes at } \\
\mathbf{4} \text { years of age }\end{array}$ & TSH $(\mathrm{mU} / \mathrm{l})$ & OC pesticides $^{\mathrm{b}}$ & $\boldsymbol{\alpha}$-TEXB $+\boldsymbol{\beta}$-TEXB \\
\hline General cognitive & $-5.51(-10.54,-0.48)^{\star}$ & $-6.34(-12.32,-0.36)^{\star}$ & $-5.35(-10.24,-0.45)^{\star}$ \\
Executive function & $-5.20(-10.50,-0.11)^{\star}$ & $-7.85(-14.04,-1.67)^{\dagger}$ & $-5.05(-10.27,0.18)$ \\
\hline
\end{tabular}

${ }^{\star} P<0.05 ;{ }^{\dagger} P<0.01$. MSCA outcome data are standardised (Mean: 100; S.D.: 15).

${ }^{a}$ Each row represents three models of the association between log-transformed TSH concentrations and MSCA normal-distributed outcomes, adjusted for birth length, gestational age, maternal age, parity, breastfeeding, maternal and paternal education, motherto-infant attachment, child's age and school term and psychologist administering the test.

${ }^{\mathrm{b}}$ Additionally adjusted for placental concentration of $17 \mathrm{OC}$ ( $\geq \mathrm{LD}$, excepting for $p, p^{\prime}$-DDE, which was introduced as continuous).

${ }^{\mathrm{c}}$ Additionally adjusted for the combined xeno-oestrogenic effect of the $\alpha$ fraction $(\alpha-$ TEXB) and the $\beta$ fraction ( $\beta$-TEXB) of placenta samples ( $\geq$ LD). 
perceptual performance MSCA outcomes (44), consistent with the present findings.

By contrast, other authors reported that higher newborn $\mathrm{T}_{4}$ was unexpectedly associated with lower scores on the visual recognition memory test at the age of 6 months but not with scores for verbal abilities, intelligence or visual motor abilities at the age of 3 years (45). Another study observed no neurological impairment in infants aged $<1$ year born to mothers with elevated TSH during pregnancy (46). Furthermore, neonatal $\mathrm{T}_{4}$ levels were not associated with the risk of a heterogeneous group of developmental diagnoses in 5-12-year-old children, including attention deficit disorder, autism spectrum disorder, behavioural disorder, cognitive disorder, developmental delay, emotional disorder, learning disability and speech/ language disorder (47). A recent case-control study in Southern Spain observed a superior psychometric and behavioural development among children whose mothers had received iodine supplementation compared with the children of non-supplemented mothers; cord blood TSH was significantly higher in infants of supplemented mothers (16). A study of Sicilian children reported that a mild to moderate ID was associated with a reduced IQ and attention deficit hyperactivity disorder (13). Finally, increases in the risk of delay in gross and fine motor coordination and socialisation in 18-month infants were found to result from a period of isolated hypothyroxinaemia in pregnant women from a coastal region in Spain with mild ID (15).

The timing of TH action is crucial for neurodevelopment, and the effects of TH status may therefore differ among pregnant women, neonates and children. In the neonatal and postnatal periods, neurological development still depends on THs, whose supplies to the brain are entirely derived from the child and are critical for continuing maturation (6). It has been demonstrated that THs during early pregnancy influence later child development, although the neurological effects of THs may be less severe in neonates. This study demonstrated that higher newborn TSH levels within a normal reference range were related to lower intelligence, as measured by the general cognitive score, and to impairment of higher psychological processes (executive function) at the age of 4 years. These findings support the view that moderate alterations in neonatal thyroid status may play a role in subsequent neurodevelopment. Even subtle cognitive delays at this age may lead to sub-clinical but permanent decreases in IQ and to long-lasting effects on educational and social development (48). Hence, they should be considered clinically relevant, since early identification of sub-optimal cognitive functioning is necessary to adopt preventive measures.

The study limitations include the fact that only boys were studied; the non-assessment of behavioural or psychopathological outcomes such as attention deficit, social or emotional disorders, which have also been associated with early thyroid status $(15,43,44)$ and the absence of measurements of newborn $\mathrm{T}_{4}, \mathrm{~T}_{3}$ or thyroid axis hormones other than TSH, which would have yielded complete information on the newborn's thyroid regulatory system. In fact, recent studies have reported the unexpected finding of a positive correlation between TSH and free $\mathrm{T}_{4}$ levels in cord blood correlate $(14,49)$, suggesting that TSH elevations should not necessarily be interpreted as indicating a potentially harmful effect on the child. There is a progressive modulation of the set point for $\mathrm{T}_{4}$ negative feedback regulation of TSH secretion in infants, which implies that TSH production is overstimulated during gestation, decreasing from postnatal age of around 2 weeks (49). Owing to this decline in TSH levels over the first days of life, newborns with elevated TSH should be evaluated for congenital hypothyroidism with repeat $\mathrm{TSH}$ and free $\mathrm{T}_{4}$ measurements. However, it is recognised that TSH measurement offers higher sensitivity to detect thyroid dysfunction in comparison with $\mathrm{T}_{4}$ or $\mathrm{T}_{3}$ testing, since subtle alterations in $\mathrm{T}_{4}$ or $\mathrm{T}_{3}$ within the normal reference range may result in an amplified alteration of TSH (50). The study strengths include the longitudinal design, the considerable number of covariates considered (e.g. breastfeeding and parental attachment) and, most importantly, the fact that we examined the association between TSH and neurodevelopment in typically developing children from the general population. In addition, this is the first report to evaluate the potential confounding effect of prenatal exposure to a wide range of ED, environmental chemicals and their combined oestrogenic effect on the association under study.

To date, epidemiological studies have described associations of early exposure to OC compounds with TH levels (20-26) and with neurodevelopment impairment (51-53). However, a consistent influence on thyroid status and neurodevelopment of many OC compounds at environmental background levels has not been established yet. Humans may be exposed to mixtures of these and numerous other compounds, hampering the prediction of effects on TH levels. We have previously demonstrated the ubiquity of exposure to OC xeno-oestrogens in the INMA-Granada cohort (54). In this study, prenatal exposure to 17 OC pesticides or the xeno-oestrogenic burden in the placentas were observed to modify the impact of neonatal TSH on neurodevelopment, in agreement with the suspected capacity of OCs to interfere with the thyroid system (20-26).

In conclusion, this study of a birth cohort in Southern Spain revealed an impaired mental development at 4 years of age in children with higher neonatal TSH levels compared with children with lower neonatal TSH levels within the normal reference range. These findings indicate that a more thorough screening for neonatal thyroid deficiency is required to prevent long-term developmental effects. Further research is warranted into the influence on neurodevelopment of marginally altered TSH concentrations in newborns and into 
causal relationships between ED, environmental chemicals and TH status.

\section{Declaration of interest}

The authors declare that there is no conflict of interest that could be perceived as prejudicing the impartiality of the research reported.

\section{Funding}

This work was supported by the Consejería de Salud de la Junta de Andalucía (grant number P09-CTS-5488); the Spanish Ministry of Health (grant number FIS07/0252) and the European Commission (grant number CONTAMED-FP7-ENV-2007-1-212502 and EUS2008-03574).

\section{Acknowledgements}

The authors are grateful to Richard Davies for editorial assistance. The results would not have been achieved without the selfless collaboration of the study participants, the staff at the Department of Gynaecology and Paediatrics of the San Cecilio University Hospital and at the Environmental Health Department of the Consejería de Salud de la Junta de Andalucía.

\section{References}

1 Williams GR. Neurodevelopmental and neuropsychological actions of thyroid hormone. Journal of Neuroendocrinology 2008 20 784-794. (doi:10.1111/j.1365-2826.2008.01733.x)

2 Zoeller RT \& Rovet J. Timing of thyroid hormone action in the developing brain: clinical observations and experimental findings. Journal of Neuroendocrinology 200416 809-818. (doi:10.1111/ j.1365-2826.2004.01243.x)

3 Bernal J. Thyroid hormone receptors in brain development and function. Nature Clinical Practice. Endocrinology \& Metabolism 2007 3 249-259. (doi:10.1038/ncpendmet0424)

4 Calvo RM, Jauniaux E, Gulbis B, Asuncion M, Gervy C, Contempre B \& Morreale de Escobar G. Fetal tissues are exposed to biologically relevant free thyroxine concentrations during early phases of development. Journal of Clinical Endocrinology and Metabolism 200287 1768-1777. (doi:10.1210/jc.87.4.1768)

5 De Escobar GM, Obregón MJ \& Escobar del Rey F. Maternal thyroid hormones early in pregnancy and fetal brain development. Best Practice and Research. Clinical Endocrinology and Metabolism 2004 18 225-248. (doi:10.1016/j.beem.2004.03.012)

6 De Escobar G, Obregón MJ \& Escobar del Rey F. Is neuropsychological development related to maternal hypothyroidism or to maternal hypothyroxinemia? Journal of Clinical Endocrinology and Metabolism 200085 3975-3987. (doi:10.1210/jc.85.11.3975)

7 Glinoer D \& Delange F. The potential repercussions of maternal, fetal, and neonatal hypothyroxinemia on the progeny. Thyroid 200010 871-877. (doi:10.1089/thy.2000.10.871)

8 Delange $\mathrm{F}$. Iodine deficiency as a cause of brain damage. Postgraduate Medical Journal 200177 217-220. (doi:10.1136/ pmj.77.906.217)

9 Zoeller RT. Transplacental thyroxine and fetal brain development. Journal of Clinical Investigation 2003111 954-957. (doi:10. 1172/JCI18236)

10 Santiago-Fernández P, Torres-Barahona R, Muela-Martínez JA, Rojo-Martínez G, García-Fuentes E, Garriga MJ, Leon AG \& Soriguer F. Intelligence quotient and iodine intake: a crosssectional study in children. Journal of Clinical Endocrinology and Metabolism 200489 3851-3857. (doi:10.1210/jc.2003031652)

11 Haddow JE, Palomaki GE, Allan WC, Williams JR, Knight GJ, Gagnon J, O'Heir CE, Mitchell ML, Hermos RJ, Waisbren SE, Faix JD \& Klein RZ. Maternal thyroid deficiency during pregnancy and subsequent neuropsychological development of the child. New England Journal of Medicine $1999 \mathbf{3 4 1}$ 549-555. (doi:10.1056/ NEJM199908193410801)

12 Pop VJ, Kuijpens JL, van Baar AL, Verkerk G, van Son M, de Vijlder JJ, Vulsma T, Wiersinga WM, Drexhage HA \& Vader HL. Low maternal free thyroxine concentrations during early pregnancy are associated with impaired psychomotor development in infancy. Clinical Endocrinology 199950 149-155. (doi:10.1046/j.1365-2265.1999.00639.x)

13 Vermiglio F, Lo Presti VP, Moleti M, Sidoti M, Tortorella G, Scaffidi G, Castagna MG, Mattina F, Violi MA, Crisà A, Artemisia A \& Trimarchi F. Attention deficit and hyperactivity disorders in the offspring of mothers exposed to mild-moderate iodine deficiency: a possible novel iodine deficiency disorder in developed countries. Journal of Clinical Endocrinology and Metabolism 2004 89 6054-6060. (doi:10.1210/jc.2004-0571)

14 De Escobar G, Obregón MJ \& Escobar del Rey F. Iodine deficiency and brain development in the first half of pregnancy. Public Health Nutrition 200710 1554-1570. (doi:10.1017/S1368980007360928)

15 Berbel P, Mestre JL, Santamaría A, Palazón I, Franco A, Graells M, González-Torga A \& de Escobar GM. Delayed neurobehavioral development in children born to pregnant women with mild hypothyroxinemia during the first month of gestation: the importance of early iodine supplementation. Thyroid 200919 511-519. (doi:10.1089/thy.2008.0341)

16 Velasco I, Carreira M, Santiago P, Muela-Martínez JA, GarcíaFuentes E, Sánchez-Muñoz B, Garriga MJ, GonzálezFernández MC, Rodríguez A, Caballero FF, Machado A, González-Romero S, Anarte MT \& Soriguer F. Effect of iodine prophylaxis during pregnancy on neurocognitive development of children during the first two years of life. Journal of Clinical Endocrinology and Metabolism 200994 3234-3241. (doi:10.1210/jc.2008-2652)

17 Oakley GA, Muir T, Ray M, Girdwood RWA, Kennedy R \& Donaldson MDC. Increased incidence of congenital malformations in children with transient thyroid-stimulating hormone elevation on neonatal screening. Journal of Pediatrics 1998132 726-730. (doi:10.1016/S0022-3476(98)70369-5)

18 Simpson J, Williams FL, Delahunty C, vanToor H, Wu SY, Ogston SA, Visser TJ, Hume R \& Scottish Preterm Thyroid Group. Serum thyroid hormones in preterm infants and relationships to indices of severity of intercurrent illness. Journal of Clinical Endocrinology and Metabolism 200590 1271-1279. (doi:10.1210/jc.2004-2091)

19 Anderson GW. Thyroid hormones and the brain. Frontiers in Neuroendocrinology 200122 1-17. (doi:10.1006/frne.2000.0208)

20 Chevrier J, Eskenazi B, Holland N, Bradman A \& Barr DB. Effects of exposure to polychlorinated biphenyls and organochlorine pesticides on thyroid function during pregnancy. Americam Journal of Epidemiology 2008168 298-310. (doi:10.1093/aje/ kwn136)

21 Wang SL, Su PH, Jong SB, Guo YL, Chou WL \& Päpke O. In utero exposure to dioxins and polychlorinated biphenyls and its relations to thyroid function and growth hormone in newborns. Environmental Health Perspectives 2005113 1645-1650. (doi:10. 1289/ehp.7994)

22 Takser L, Mergler D, Baldwin M, Smargiassi A \& Lafond J. Thyroid hormones in pregnancy in relation to environmental exposure to organochlorine compounds and mercury. Environmental Health Perspectives 2005113 1039-1045. (doi:10.1289/ehp.7685)

23 Maervoet J, Vermeir G, Covaci A, Nelen V, Baeyens W, Schepens P \& Viaene MK. Association of thyroid hormone concentrations with levels of organochlorine compounds in cord blood of neonates. Environmental Health Perspectives 2007115 1780-1786. (doi:10. 1289/ehp.10486)

24 Álvarez-Pedrerol M, Guxens M, Ibarluzea J, Rebagliato M, Rodriguez A, Espada M, Goñi F, Basterrechea M \& Sunyer J. Organochlorine compounds, iodine intake, and thyroid hormone levels during pregnancy. Environmental Science and Technology 200943 7909-7915. (doi:10.1021/es9007273)

25 Lopez-Espinosa MJ, Vizcaino E, Murcia M, Llop S, Espada M, Seco V, Marco A, Rebagliato M, Grimalt JO \& Ballester F. Association 
between thyroid hormone levels and 4,4'-DDE concentrations in pregnant women (Valencia, Spain). Environmental Research 2009 109 479-485. (doi:10.1016/j.envres.2009.02.003)

26 Lopez-Espinosa MJ, Vizcaino E, Murcia M, Fuentes V, Garcia AM, Rebagliato M, Grimalt JO \& Ballester F. Prenatal exposure to organochlorine compounds and neonatal thyroid stimulating hormone levels. Journal of Exposure Science and Environmental Epidemiology 2009. (doi:10.1038/jes.2009.47)

27 Porterfield SP. Thyroidal dysfunction and environmental chemicals potential impact on brain development. Environmental Health Perspectives 2000108 (Supplement 3) 433-438. (doi:10.2307/ 3454533)

28 Boas M, Feldt-Rasmussen U, Skakkebaek NE \& Main KM. Environmental chemicals and thyroid function. European Journal of Endocrinology 2006154 599-611. (doi:10.1530/eje.1.02128)

29 Ribas-Fitó N, Ramon R, Ballester F, Grimalt JO, Marco A, Olea N, Posada M, Rebagliato M, Tardon A, Torrent M \& Sunyer J. Child health and the environment: the INMA Spanish study. Paediatric and Perinatal Epidemiology 200620 403-410. (doi:10.1111/ j.1365-3016.2006.00745.x)

30 Fernández MF, Olmos B, Granada A, Lopez-Espinosa MJ, MolinaMolina JM, Fernández JM, Cruz M, Olea-Serrano MF \& Olea N. Human exposure to endocrine disrupting chemicals and prenatal risk factors for cryptorchidism and hypospadias. A nested case-control study. Environmental Health Perspectives 2007115 (Supplement 1) 8-14. (doi:10.1289/ehp.9351)

31 Freire C, Ramos R, Lopez-Espinosa MJ, Díez S, Vioque J, Ballester F \& Fernández MF. Hair mercury levels, fish consumption, and cognitive development in preschool children from Granada, Spain. Environmental Research 2010110 96-104. (doi:10.1016/ j.envres.2009.10.005)

32 Freire C, Ramos R, Puertas R, Lopez-Espinosa MJ, Julvez J, Aguilera I, Cruz F, Fernandez MF, Sunyer J \& Olea N. Association of traffic-related air pollution with cognitive development in children. Journal of Epidemiology and Community Health 201064 223-228. (doi:10.1136/jech.2008.084574)

33 Cortés Castell E, Chamorro Ureña F, Dulín Iñíguez E, Eguileor Gurtubai I, Espada Sáenz-Torre M, Remón Alvarez-Arenas J, Pámpols Ros T \& on behalf of the Comisión de Errores Metabólicos Congénitos de la Sociedad Española de Bioquímica Clínica y Patología Molecular (SEQC). Neonatal screening and collaboration among scientific institutions. Anales Españoles de Pediatría 200256 201-203.

34 Fernández MF, Rivas A, Olea-Serrano F, Cerrillo I, MolinaMolina JM, Araque P, Martínez-Vidal JL \& Olea N. Assessment of total effective xenoestrogen burden in adipose tissue and identification of chemicals responsible for the combined estrogenic effect. Analytical and Bioanalytical Chemistry 2004379 163-170. (doi:10.1007/s00216-004-2558-5)

35 Lopez-Espinosa MJ, Silva E, Granada A, Molina-Molina JM, Fernández MF, Aguilar-Garduño C, Olea-Serrano F, Kortenkamp A \& Olea N. Assessment of the total effective xenoestrogenic burden in extracts of human placenta. Biomarkers 200914 271-277. (doi:10.1080/13547500902893744)

36 McCarthy D. Manual for the McCarthy Scales of Children's Abilities. New York, NY: Psychological Corp, 1972. Spanish Adaptation (1996), Madrid, Spain: TEA Ediciones, SA: 1996.

37 Julvez J, Ribas-Fitó N, Torrent M, Forns M, Garcia-Esteban R \& Sunyer J. Maternal smoking habits and cognitive development of children at age 4 years in a population-based birth cohort. International Journal of Epidemiology 200736 825-832. (doi:10. 1093/ije/dym107)

38 Jacobson JL \& Jacobson SW. Methodological issues in research on developmental exposure to neurotoxic agents. Neurotoxicology and Teratology 200527 395-406. (doi:10.1016/j.ntt.2005.01.009)

39 Condon JT \& Corkindale CJ. The assessment of parentto-infant attachment: development of a self-report questionnaire instrument. Journal of Reproductive and Infant Psychology 199816 57-76. (doi:10.1080/02646839808404558)
40 Choudhury N \& Gorman KS. Subclinical prenatal iodine deficiency negatively affects infant development in northern China. Journal of Nutrition 2003133 3162-3165.

41 Glinoer D \& Rovet J. Gestational hypothyroxinemia and the beneficial effects of early dietary iodine fortification. Thyroid 2009 19 431-434. (doi:10.1089/thy.2009.1572)

42 Pop VJ, Brouwers EP, Vader HL, Vulsma T, van Baar AL \& Vijlder JJ. Maternal hypothyroxinemia during early pregnancy and subsequent child development: a 3-year follow-up study. Clinical Endocrinology 200359 282-288. (doi:10.1046/j.1365-2265. 2003.01822.x)

43 Simic N, Asztalos EV \& Rovet J. Impact of neonatal thyroid hormone insufficiency and medical morbidity on infant neurodevelopment and attention following preterm birth. Thyroid 2009 19 395-401. (doi:10.1089/thy.2008.0282)

44 Álvarez-Pedrerol M, Ribas-Fitó N, Torrent M, Julvez J, Ferrer C \& Sunyer J. TSH concentration within the normal range is associated with cognitive function and ADHD symptoms in healthy preschoolers. Clinical Endocrinology 200766 890-898. (doi:10. $1111 /$ j.1365-2265.2007.02871.x)

45 Oken E, Braverman LE, Platek D, Mitchell ML, Lee SL \& Pearce EN. Neonatal thyroxine, maternal thyroid function, and child cognition. Journal of Clinical Endocrinology and Metabolism 2009 94 497-503. (doi:10.1210/jc.2008-0936)

46 Orito Y, Oku H, Kubota S, Amino N, Shimogaki K, Hata M, Manki K, Tanaka Y, Sugino S, Ueta M, Kawakita K, Nunotani T, Tatsumi N, Ichihara K, Miyauchi A \& Miyake M. Thyroid function in early pregnancy in Japanese healthy women: relation to urinary iodine excretion, emesis, and fetal and child development. Journal of Clinical Endocrinology and Metabolism 200994 1683-1688. (doi:10.1210/jc.2008-2111)

47 Soldin OP, Lai S, Lamm SH \& Mosee S. Lack of a relation between human neonatal thyroxine and pediatric neurobehavioral disorders. Thyroid 200313 193-198. (doi:10.1089/10507250 3321319503)

48 Grandjean P \& Landrigan PJ. Developmental neurotoxicity of industrial chemicals. Lancet $2006 \mathbf{3 6 8}$ 2167-2178. (doi:10. 1016/S0140-6736(06)69665-7)

49 Hume R, Simpson J, Delahunty C, van Toor H, Wu SY, Williams FL, Visser TJ \& with collaboration from the Scottish Preterm Thyroid Group. Human fetal and cord serum thyroid hormones: developmental trends and interrelationships. Journal of Clinical Endocrinology and Metabolism 200489 4097-4103. (doi:10. 1210/jc.2004-0573)

50 The National Academy of Clinical Biochemistry. Guía de consenso para el diagnóstico y seguimiento de la enfermedad tiroidea. Acta Bioquímica Clínica Latinoamericana 2007 41 87-119.

51 Ribas-Fitó N, Torrent M, Carrizo D, Muñoz-Ortiz L, Júlvez J, Grimalt JO \& Sunyer J. In utero exposure to background concentrations of DDT and cognitive functioning among preschoolers. Americam Journal of Epidemiology 2006 164 955-962. (doi:10.1093/aje/kwj299)

52 Eskenazi B, Marks AR, Bradman A, Fenster L, Johnson C, Barr DB \& Jewell NP. In utero exposure to dichlorodiphenyltrichloroethane (DDT) and dichlorodiphenyldichloroethylene (DDE) and neurodevelopment among young Mexican American children. Pediatrics 2006118 233-241. (doi:10.1542/peds.2005-3117)

53 Puertas R, Lopez-Espinosa MJ, Cruz F, Ramos R, Freire C, PérezGarcía M, Abril A, Julvez J, Salvatierra M, Campoy C \& Olea N. Prenatal exposure to mirex impairs neurodevelopment at age of 4 years. Neurotoxicology 201031 154-160. (doi:10.1016/j.neuro. 2009.09.009)

54 Lopez-Espinosa MJ, Granada A, Carreño J, Salvatierra MT, Olea-Serrano F \& Olea N. Organochlorine pesticides in placentas from Southern Spain and some related factors. Placenta $2007 \mathbf{2 8}$ 631-638. (doi:10.1016/j.placenta.2006.09.009)

Received 11 August 2010

Accepted 9 September 2010 